\title{
Blended Learning System Performance Evaluation
}

\author{
Naser Zaeri \\ Faculty of Computer Studies \\ Arab Open University \\ P.O. Box 3322 Safat 13033 Kuwait
}

\begin{abstract}
In this paper, the use of the blended learning pedagogy as a teaching environment is studied. This pedagogy is based on a mixture of collaborative learning, problem-based learning and independent learning. Also, it is realized as a combination of a face-to-face environment and online learning, using a proprietary learning management system. More precisely, the methodological approach implemented by the Arab Open University is explored. The Arab Open University has twelve different branches distributed in eight different countries. In addition, the blended learning course design is described and the fulfillment of the corresponding learning outcomes is investigated. The study concludes that the technology provides with more learning choices. Among the choices is the blended learning that has several advantages and strength when compared to its counterpart, the classical learning. However, there are some challenges that need to be considered as well.
\end{abstract}

\section{General Terms}

Information Technology, Computer Science, E-learning.

\section{Keywords}

Blended Learning, Pedagogy, Learning management system.

\section{INTRODUCTION}

The advent of the modern knowledge society necessitates changes in educational processes, new forms of education and training, and new skills. Merely altering the subject matter taught would be inadequate to bring about these changes; fundamental shifts in teaching methodology are essential. Although these changes are necessary at every level of education, they are particularly important at the higher education level [1]. The role of the instructor must be redefined so as to accomplish a shift in pedagogy from an instructor-centered to a learner-centered environment. The educational system should provoke an interest in independent learning, and prepare the students for lifelong learning, which is a necessary skill for successful participation in the knowledge society.

Today's technology and the development in communication systems facilitate the delivery of learning materials, discussion forum, file transfer and so forth. Students are allowed to access the learning materials, participate the learning process, and join the discussion at any place and any time. This flexibility essentially encourages a learner-centered and goal-oriented delivery strategy which can take into account the differences among learners. Information and Communication Technology (ICT) is an indispensable part of modern education, especially because of the opportunities this technology offers to accomplish the new teaching paradigm. By March 2013, around 2.75 billion people were online (38.8

$\%$ of the world population) indicating a huge potential market for online educators [2]. Many developed countries have reserved a big proportion of education funding to support their e-learning strategies to enhance the education exports.

The vast majority of today's generation has several means of communication: mobile phones, iPods, etc. These means facilitate students' interaction with each other, their courses, and the information they need. They can use different search engines, access electronic encyclopedias, participate in various blogs, and tune into YouTube. Dziuban et al. [3] found from interviews conducted at the University of Central Florida that students start surfing as soon as the lecture gets boring. According to [3], the new generational learning skills are play, performance, simulation, multitasking, trans-media navigation, networking, and negotiation. These learning styles reflect this generation's preference for graphics vs. text and learning by fantasy vs. reality [4].

In this paper, the Arab Open University (AOU) is studied as a model that implements new learning pedagogy. AOU has twelve different branches and centers distributed in eight different Arab countries. This paper considers how today's technology development can be adopted in learning and teaching systems. With near ten years of practicing blended learning, the AOU has earned much experience in e-learning, from the development of a learning management system to the development of e-courses (or blended courses). E-learning is classified as synchronous or asynchronous. Both terms refer to "the extent to which a course is bound by place and/or time" [1]. Synchronous simply means that two or more events occur at the same time, while asynchronous means that two or more events do not occur at the same time. The computer system that is situated in such academic environment must be capable of autonomous action in order to meet its design objectives. This system should be intelligent and capable of flexible autonomous action in order to meet its design objectives. As such, it should be adaptable, interactive, distributed, collaborative, and secured to support instructional design, retrieve relevant learning materials, process, and analyze data. In this regard, several issues associated with education in a technology-intensive environment in the Arab World are explored: the demographic distribution, opportunities, challenges, and student satisfaction.

In this analysis, more than 9,300 surveys for 115 different courses from the different academic programs have been studied. Further, the hypothesis: "Does implementing the high-end technology should disregard the importance of high quality learning and teaching?" is discussed. Some argued that the loss of face-to-face contact diminished the value of education and the students did not learn as well or as much. Others argued that the performance was the same, regardless of whether a course is taken traditionally or online. The rest of 
the paper is organized as follows. Section 2 presents a brief literature review. Blended learning course design is discussed in section 3. The learning management system is elaborated in section 4. Section 5 furnishes the analysis and results interpretation. Finally, the paper is brought to conclusion in section 6.

\section{LITERATURE REVIEW}

Given the rapid changes in communication and computer technologies during the last two decades, many universities throughout different parts of the world have been investing a huge amount of resources to implement their e-learning platform or environment which are mostly learning management systems, such as Blackboard and Moodle [5, 6]. Capuano et al. [7] proposed a tutoring system for distance learning that would be useful for several knowledge domains. The architecture of this system composed of three different parts. The first part is the "Evaluation" part that is responsible for evaluating and updating cognitive states and the whole student models. The other two parts are the "Affective" part and the "Pedagogical" part. "Affective" part is concerned with evaluating and updating learning preferences. The "Pedagogical" part is responsible of evaluating and updating the curriculums.

Andreev and Troyanova [8] presented a research that concentrates on the service-oriented approach to the design of a collaborative learning environment with virtual organization. Their approach to the architectural design of the e-learning environment considered the environment as a source of resources where two types of resources were encountered: learning resources and instructional resources, both are shared among two dynamic collections of individuals: learners and instructors. Regueras et al. [9] examined the effectiveness of competitive learning in combination with collaborative learning to study the effects of e-learning on university students. In order to provide communication facilities and flexibility in the competition when necessary, a telematic tool for active learning was used. Masum and Ishizuka [10] provided a visualization model which consists of a number of components. The users interact with the system through a character-agent enabled user interface.

Thyagharajan and Nayak [11] addressed the problems of automatically selecting and integrating appropriate learning materials for a learner using web services based on the learner's initial knowledge, goals, and preferences. The approach is based on fulfilling learning objectives based on a dynamic supply of services. Kim et al. [12] proposed an elearning content organization scheme that is based on a process-driven approach. The sharable content object sequencing and navigation information are explicitly defined through a process-driven content organization scheme. Alexakos et al. [13] presented a platform that integrates intelligent agents in a legacy e-learning environment. They have introduced a scalable and interoperable integration platform supporting various assessment agents. Karger et al. [14] presented a technique based on "Preference Handling" for representing the learner's preferences and exploited this representation for selecting learning resources that best match these preferences. The technique is applicable during the process of searching for learning resources, the adaptation of course delivery to the goals, interests, and knowledge that are stated in the form of preferences. Kashfi and Rasais [15] proposed a service based architecture for developing a distributed e-learning system that uses a grid technology. A grid technology is suitable when the resources need be shared by direct access to computers, software, and other resources.

Shang et al. [16] presented a web-based distributed environment for active learning that supports studentcentered, self-paced, and interactive learning approach. Students' learning-related profiles, such as learning styles and background knowledge, were used in selecting, organizing, and presenting learning materials. This system ties the students' web clients and the underlying information servers that are used for courseware and student profiles together with the multi-agent resource management. Tseng et al. [17] proposed an adaptive learning approach based upon two main sources of personalization information, namely learning behavior and personal learning style. In this approach, a questionnaire was used to determine the initial learning styles of students.

\section{BLENDED LEARNING COURSE DESIGN}

Blended learning should not be mistakenly defined as distance learning. Distance learning takes place when the students are geographically remote from the education institution at which they are registered. They will also be remote from their instructors and other students for most or all of the time [4]. On the other hand, blended learning presents a very important characteristic of process-oriented e-learning systems. It realizes a way of communication between a teacher and a learner by offering an adaptive teaching (a learner-centered teaching process) [8]. These learning systems can guarantee the choice of a didactical method that is suitable for a solid learning style. The adaptive behavior of the blended learning systems can be represented by the following categories [18]: adaptive interaction, adaptive course delivery and adaptive collaboration support. The process-oriented e-learning systems can ensure an adaptive interaction between the teacher and learner through the provision of learning materials that are suitable for the learner. As such, the interaction between the student and the environment has to give the student the possibility of using the learning resources. Its objective is to ensure a flexible and coordinated resource sharing among dynamic collection of the students and cooperative use of resources.

Furthermore, blended learning is based on various combinations of classical face to face lectures, learning over the Internet, and learning supported by other technologies, aimed at creating the most efficient learning environment. It also incorporates other elements such as technology and media for learning content delivery, group and individual learning activities, and synchronous and asynchronous interactions. The ultimate goal is to choose an intelligent mixture that will highly motivate the students, and assist them in successfully mastering the course. So, in this model of teaching and learning, significant amounts of face-to-face elements are replaced by technology-mediated teaching.

The learning system at the AOU is built and developed based on two important international concepts of learning: 1) Bloom's Digital Taxonomy [19], and 2) SEEC [20]. They are standard and very famous concepts with criteria defined and designed for different levels of learners. The task of designing a module passes through the following stages:

$i$. Analyzing: the situational context of the module is analyzed. This includes the delivery mode, the diverse nature of the students (fresh graduates/working adults) and the learning resources available from the publishers who provide learning 
materials, solutions manuals, animation/simulations and videos.

ii. Planning: this includes the following factors:

- $\quad$ Level of module

- Is the module required or elective?

- Based on textbook and/or course pack?

- Requires activities outside the class?

- Pre-requisite modules or any specified entry requirements

- The context of the module within the curriculum

- Module aims and the student learning outcomes such as (knowledge and understanding, cognitive skills, practical and professional skills, and key transferable skills.)

iii. Conducting: this stage includes the selection of the appropriate and effective teaching methods. The major outcome of this stage is deciding the necessary credit hours to be assigned to the course.

iv. Assessing: the assessment tackles two different kinds, the formative assessment through the midterm assessment (MTA) and tutor-marked assignment (TMA), and the summative assessment at the end of term through the final examination.

v. Instructor feedback and reflection: the instructors reflect their viewpoint and feedback about the course content and learning process during the semester through the various meetings which are held at different levels and hierarchies.

\section{LEARNING MANAGEMENT SYSTEM (LMS)}

Blended learning should be well integrated with IT support services, and the course development should be the concerted effort of the academic and IT staff. This will encourage smooth development and delivery of the courses, and this integration would enhance better communication and cooperation. AOU provides the information and learning materials online, in the form of course websites. Access to these websites is likely to be restricted and the student will need a username and password from the technical support to be able to use them. Materials are often available within the virtual learning environment (VLE) of the course, the LMS. LMS is a software application or web-based technology used to plan, implement, and assess a specific learning process. Typically, LMS is an adaptive hypermedia that provides the instructor with a way to create and deliver content, monitor student participation, and assess student performance. An LMS may also provide students with the ability to use interactive features such as threaded discussions, video conferencing, and discussion forums, as shown in Figure 1. The LMS adapted in the AOU uses a well-known model of the Modular Object Oriented Dynamic Learning Environment (MOODLE) [6]. Student interaction is supported through both synchronous and asynchronous communication forums. Automatic creation of groups based on various criteria, intergroup peer-evaluation, and file sharing functionality is available. Tools for course management and for assignments grading are also employed. The LMS will typically have some or all of the following information/features:

- Program and module information
- Learning outcomes for each unit of study

- Course materials and lectures

- Assessment details, including dates for submission of assignments

- The facility to submit assignments for marking

- Interactive learning materials

- Opportunities for self-assessment questions and feedback

- $\quad$ MTA and TMA grades

- Links to other supplementary resources
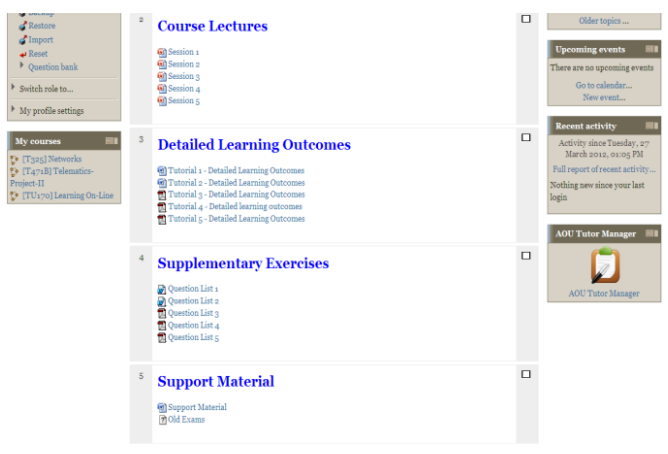

(a)

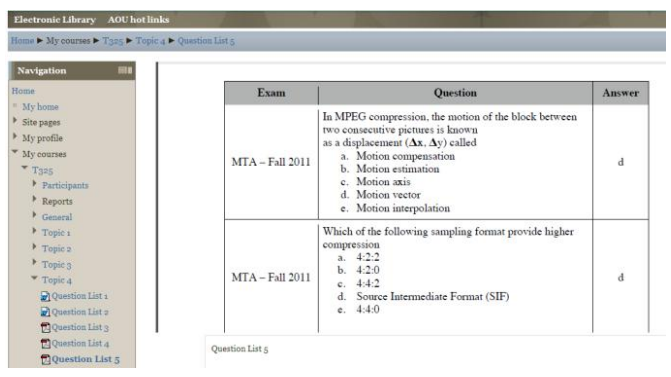

(b)

Figure 1. Snapshots of LMS links to different T325 course materials and resources are shown in (a) and (b)

\section{SYSTEM ANALYSIS AND RESULTS INTERPRETATION}

In order to properly analyze the blended system performance and the effect of technology on students' education, the various levels of effectiveness and efficiency of the numerous factors related to this "interconnected learning network" need to be inspected. These factors are related either directly, or indirectly, to the different system's stakeholders: student, instructor (or tutor), learning material (course content), learning medium, environment, and administrative management. In addition, several studies [3, 21, 22] suggest that students' satisfaction and motivation are important factors in measuring the success and the effectiveness of the learning process and in discovering students' attitude toward the learning environment.

More than 9,300 surveys and questionnaires covering different aspects have been collected, studied carefully, and consequently analyzed. The central tendency in the different data is characterized by the arithmetic average. Also, the variability or scatter in the data is described by the standard 
deviation. These data summaries and displays are essential as they focus on the important features of the data. This will help in drawing specific inferences about the effect of the different factors and the effectiveness of the blended learning components. The contributors assessed each factor per responding to the measures from these surveys and answering the corresponding questions. Each item was given a maximum score of five points. The item with an average of 3.0 points or more indicates a strength and satisfaction. This agrees with what has been suggested in $[3,21]$.

\subsection{Students' Feedback Analysis}

The different academic factors are investigated and analyzed as seen and practiced by the students themselves. For example, the familiarization with the intended learning outcomes of the course, suitability of the course content with their level and the effectiveness of the TMAs and examinations during the semester. The questionnaire was distributed electronically on the LMS to enable every registered student to participate.

In analyzing the collected questionnaires, it was found that $57 \%$ of students are between 18 to 25 years old as shown in Figure 2. Again, this indicates that today's students are technology-oriented and are more convenient with the model of learning that adopts technology as a principle mean of education. From Figure 3, 80\% of respondents have a GPA greater than 2.0; with $32 \%$ having a GPA greater than 3.0 out of 4.0. This demonstrates that their performance is remarkable. Before the general results for all the courses are furnished, the course T325 is discussed as an example to further analyze the students' response to four main factors. Figure 4(a) shows the box plot distribution of the following factor: "Clarity of learning outcomes." As the plot reveals, $75 \%$ of respondents have given a score of 3.0 or above to this factor, indicating that the learning outcomes of the course were obvious and understandable. Further, the vast majority of the students were satisfied with the other factor: "course load" and found it suitable, as Figure 4(b) indicates. The other two important factors that were considered are the effectiveness of the TMA and MTA in learning and understanding the course. The construction of the TMA, and eventually the attempts made by a student in solving it, has positive effects in understanding the course concept and ideas. From Figure 5, 84\% and $85 \%$ of students gave a score of 3.0 or above for the feedback to the TMA and MTA, respectively.

Tables 1 to 4 show summaries of the results for each one of these four factors taking into consideration every program separately. In these tables, the questionnaires have been classified according to student specialization and eventually the corresponding mean and standard deviation were found. The general results from the students' perspective express a general satisfaction. Further, Table 5 summarizes the whole results for all the courses from all the different programs taking into consideration all factors under investigation. The overall responses for the factors and criteria under study were positive and have obtained a mean score of more than 3.0 out of 5.0. This shows a general success of the learning pedagogy employed by the AOU.

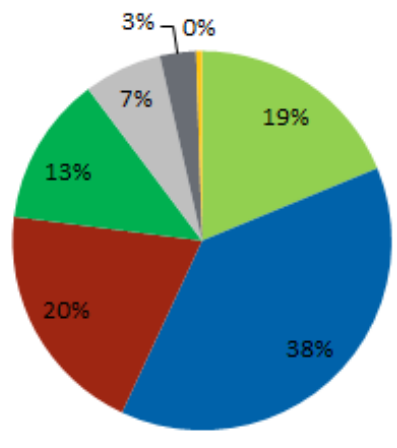

(a)

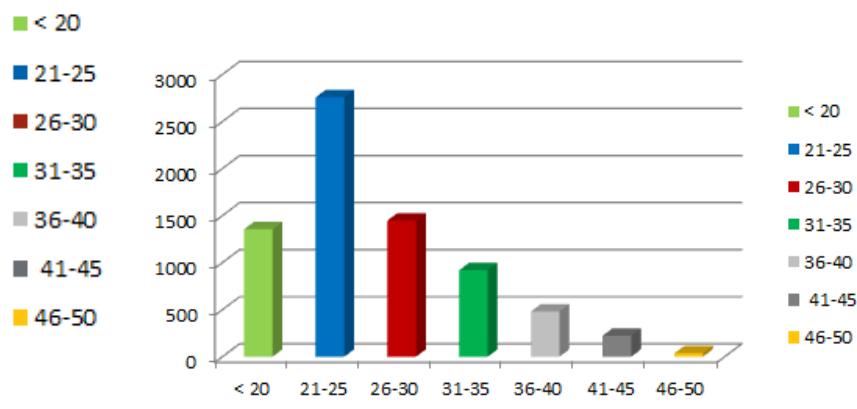

(b)

Figure 2. Students' age distribution: Pie chart in (a), and histogram distribution in (b)

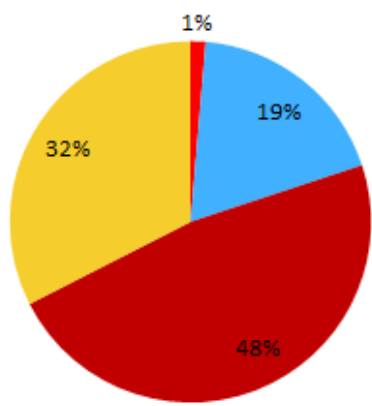

(a)

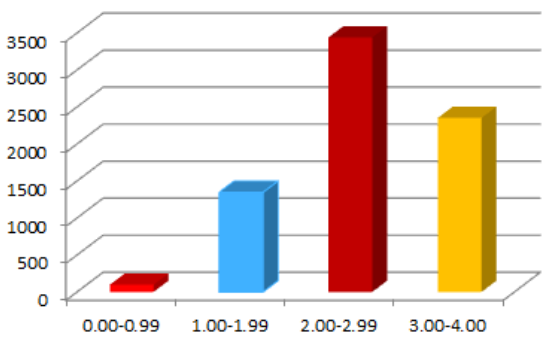

(b)

Figure 3. Students' GPA distribution: Pie chart in (a), and histogram distribution in (b) 


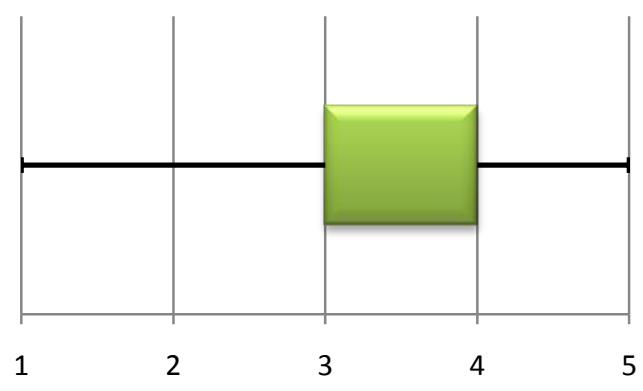

(a)

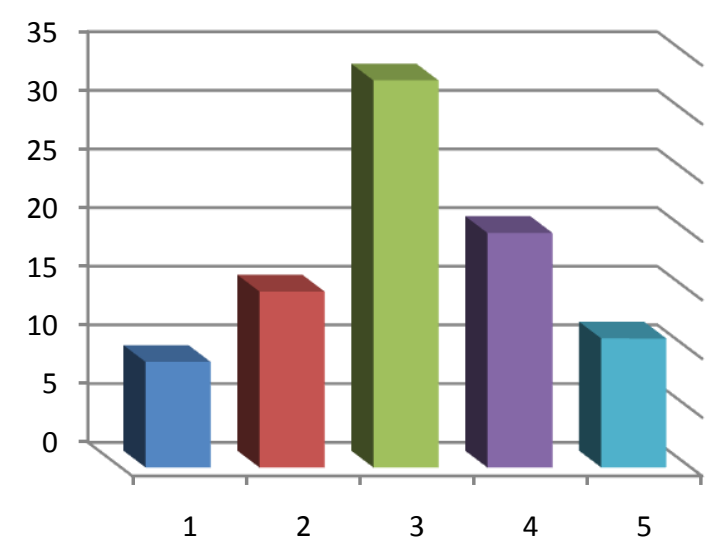

(b)

Figure 4. T325 course analysis: (a) the box plot response to the factor: "Clarity of learning outcomes" and (b) histogram distribution analysis of the factor: "Suitability of the course load work during the semester"

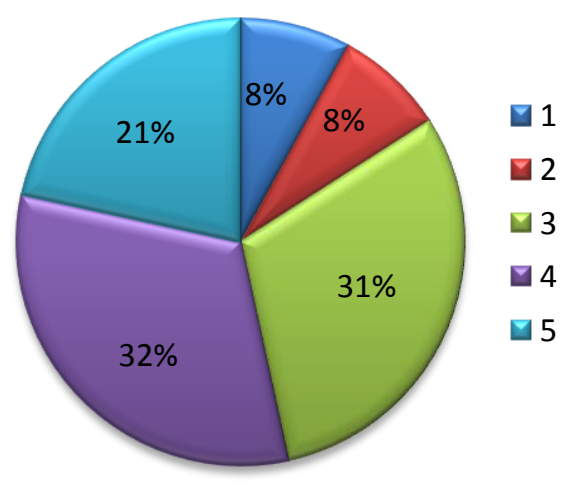

(a)

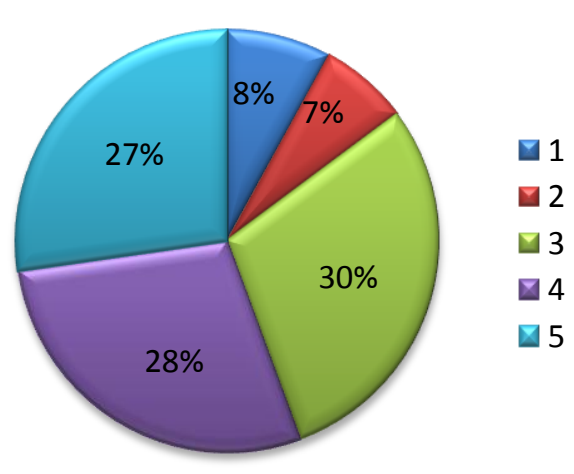

(b)

Figure 5. T325 course analysis: (a) Pie chart for the factor: "Effectiveness of TMA", and (b) Pie chart for the factor: "Effectiveness of MTA"

Table 1. Summary of results for all the courses taking each program separately into consideration when responding to: "Clarity of learning outcomes"

\begin{tabular}{|c|c|c|c|c|c|}
\hline & General Studies & Education & Business Administration & IT & English Literature \\
\hline Mean & 3.42 & 3.44 & 3.16 & 3.13 & 3.51 \\
\hline Standard Deviation & 1.18 & 1.42 & 1.13 & 1.15 & 1.14 \\
\hline
\end{tabular}

Table 2. Summary of results for all the courses taking each program separately into consideration when responding to: "Suitability of the course load work during the semester"

\begin{tabular}{|c|c|c|c|c|c|}
\hline & General Studies & Education & Business Administration & IT & English Literature \\
\hline Mean & 3.14 & 3.51 & 2.84 & 2.98 & 3.11 \\
\hline Standard Deviation & 1.15 & 1.27 & 1.15 & 1.16 & 1.18 \\
\hline
\end{tabular}


Table 3. Summary of results for all the courses taking each program separately into consideration when responding to: "Effectiveness of TMAs in learning and understanding the course"

\begin{tabular}{|c|c|c|c|c|c|}
\hline & General Studies & Education & Business Administration & IT & English Literature \\
\hline Mean & 3.37 & 3.67 & 3.16 & 3.17 & 3.41 \\
\hline Standard Deviation & 1.21 & 1.29 & 1.13 & 1.20 & 1.18 \\
\hline
\end{tabular}

Table 4. Summary of results for all the courses taking each program separately into consideration when responding to: "Effectiveness of MTAs in learning and understanding the course"

\begin{tabular}{|c|c|c|c|c|c|}
\hline & General Studies & Education & Business Administration & IT & English Literature \\
\hline Mean & 3.38 & 3.62 & 3.15 & 3.17 & 3.42 \\
\hline Standard Deviation & 1.22 & 1.22 & 1.15 & 1.19 & 1.19 \\
\hline
\end{tabular}

Table 5. Summary of the results for all the courses from all the different programs

\begin{tabular}{|c|l|c|c|}
\hline SN & \multicolumn{1}{|c|}{ Question } & Mean & $\begin{array}{c}\text { Standard } \\
\text { Deviation }\end{array}$ \\
\hline 1 & Clarity and clearness of the course materials elements (printed text, Videos, DVDs, etc) & 3.33 & 1.21 \\
\hline 2 & Clarity of learning outcomes & 3.33 & 1.20 \\
\hline 3 & How easy did you find this course? & 3.17 & 1.12 \\
\hline 4 & Usefulness of course calendar & 3.29 & 1.13 \\
\hline 5 & Suitability of the course load work during the semester & 3.12 & 1.18 \\
\hline 6 & Usefulness of electronic learning resources (LMS, E-Library) & 3.21 & 1.26 \\
\hline 7 & Effectiveness of TMAs in learning and understanding the course & 3.36 & 1.20 \\
\hline 8 & Effectiveness of MTAs in learning and understanding the course & 3.35 & 1.20 \\
\hline 9 & Was the date and time of the final examination convenient? & 3.17 & 1.20 \\
\hline
\end{tabular}

\section{CONCLUSION}

According to the results obtained from this study, the blended learning can complement (not just supplement) the traditional classroom-based teaching in many aspects. The research results have shown that student's satisfaction with the system increases in the presence of both quality online materials, and well-prepared staff leading the course in a collaborative environment. The study has shown some general system's advantages emphasized by the students. This includes the following:

- it helps learners to do preparation before class time

- the freedom to access tasks and forum at any time

- the opportunity to self-evaluate one's knowledge before the official test

- the opportunity to view and evaluate the assignments

- the participation in the group work

These results agree with other similar results presented in a number of studies [23, 24]. Moreover, the study has demonstrated that many personal attributes and skills are needed to be able to cope with the blended learning system. Those attributes may also be required by students from the traditional learning, but some take a greater significance when the student is enrolled in the blended learning system. These attributes are: time management skills, forward planning, selfdiscipline, and determination. Without these skills, the learning process would experience deep challenges and may result in a superficial learning behavior.

On the other hand, when discussing the hypothesis: "Does implementing the high-end technology should disregard the importance of high quality learning and teaching?," the obtained results disagree with this assumption or better said concept. It is always important, essential, and necessary to consider that the high quality learning and teaching play the most crucial role in the education system. An important aspect of e-learning is the use of computer as a medium for communication, research and information gathering, as well as learning tool. However, it was found that the focus should not be placed on the technical functionalities and administrative features, where the teaching and learning needs are somewhat undermined. Without that equilibrium, the positive potential for technology can lead to a diminished educational experience. Every feature of a blended learning system must be present in the proper proportion. Failure to accomplish this equilibrium can result in a less satisfied and more disengaged student population.

\section{ACKNOWLEDGMENTS}

The author would like to express his gratitude and grateful appreciation to the Kuwait Foundation for the Advancement of Sciences (KFAS) for financially supporting this study. 


\section{REFERENCES}

[1] Hoic-Bozic, N., Mornar, V., and Boticki, I. 2009. “A blended learning approach to course design and implementation," IEEE Transactions on Education, vol. 52 , no. 1

[2] Internet World Stats. 2013. [online] Available at: <http://www.internetworldstats.com/stats4.htm > [Accessed 15 July 2013].

[3] Dziuban, C., Moskal, P., Futch, L. 2007. Reactive Behavior, Ambivalance, and the Generations: Emerging Patterns in Student Evaluation of Blended Learning, University of Central Florida.

[4] Cavanagh, T. B. 2012. The postmodality era: How 'online learning' is becoming 'learning'. In D. Oblinger (Ed.), Game changers: Education and information technology. Boulder, CO: EDUCAUSE.

[5] Blackboard. 2013. [online] Available at: <http://www.blackboard.com> [Accessed 12 July 2013].

[6] moodle. 2013. [online] Available at: <http://www.moodle.org $\geq$ [Accessed 12 July 2013].

[7] Capuano, N., Marsella, M., and Salerno, S. 2000. "ABITS: An agent based intelligent tutoring system for distance learning," In Proceedings of the International Workshop on Adaptive and Intelligent Web-Based Education Systems. ITS

[8] Andreev, R. D. and Troyanova, N. V. 2006. "E-learning design: An integrated agent-grid service architecture," IEEE International Symposium on Modern Computing.

[9] Regueras, L. M., Verdú, E., Muñoz, M. F., Pérez, M. A., De Castro, J. P., and Verdú, M. J. 2009. "Effects of competitive e-learning tools on higher education students: A case study," IEEE Transactions On Education, vol. 52, no. 2.

[10] Al Masum, S. M. and Ishizuka, M. 2005. "Softwareagent architecture for interactive e-learning," in Proceedings of 1st International Conference on Web Information Systems and Technologies.

[11] Thyagharajan, K.K. and Nayak, R. 2007. "Adaptive content creation for personalized e-learning using web services," Journal of Applied Sciences Research, vol. 3, no. 9 .
[12] Kim, K.-H., Yoo, H.-J., and Kim, H.-S. 2005. "A process-driven e-learning content organization model," Fourth Annual ACIS International Conference on Computer and Information Science.

[13] Alexakos, C., Giotopoulos, K., Thermogianni, E., Beligiannis, G., and Likothanassis, S. 2006. "Integrating e-learning environments with computational intelligence assessment agents," in Proceedings of World Academy of Science, Engineering and Technology, vol. 13.

[14] Karger, P., Olmedilla, D., Abel, F., Herder, E., and Siberski, W. 2008. "What do you prefer? Using preferences to enhance learning technology," IEEE Transactions On Learning Technologies, vol. 1, no. 1.

[15] Kashfi, H. and Rasais, M. R. 2006. "A distributed service oriented e-learning environment based on grid technology," National Computer Conference.

[16] Shang, Y., Shi, H., and Chen, S.-S. 2001. "An intelligent distributed environment for active learning," ACM.

[17] Tseng, J., Chu, H.-C., Hwang, G.-J., and Tsai, C.-C. 2008. "Development of an adaptive learning system with two sources of personalization information," Computers \& Education.

[18] Paramythis, A., Loidl-Reisinger, S., and Kepler, J. 2004. "Adaptive learning environments and e-learning standards" Electronic Journal of e-Learning, vol. 2, no. 1.

[19] Churches, A. 2009. Bloom's Digital Taxonomy. [online] Available at: <http://edorigami.wikispaces.com> [Accessed 22 May 2013].

[20] SEEC. 2013. [online] Available at: <http://www.seec.org.uk/> [Accessed 20 May 2013].

[21] Levy, Y. 2007. "Comparing dropouts and persistence in e-learning courses," Computer Education, vol. 48, no. 2.

[22] Moore, J. C. 2011. "A synthesis of Sloan-C effective practices," Journal of Asynchronous Learning Networks, vol. 16 no. 1

[23] Bold, M. 2005. "Development and evaluation of a distance learning master's degree in family studies," Online Journal of Distance Learning Administration, vol. 8 , no. 3 .

[24] Dziuban, C. and Moskal, P. 2011. "A course is a course is a course: Factor invariance in student evaluation of online, blended, and face-to-face learning environments" Journal of Internet and Higher Education, vol. 14. 